\title{
KERAGAAN DAN HUBUNGAN ANTAR SIFAT BEBERAPA POPULASI JAGUNG LOKAL KEBO HASIL SELEKSI MASSA DALAM SISTEM TUMPANGSARI
}

\begin{abstract}
PERFORMANCE AND RELATIONSHIP BETWEEN SOME CHARACTERS OF LOCAL CORN POPULATION RESULT OF MASS SELECTION IN INTERCROPING CULTIVATION SYSTEM
\end{abstract}

\author{
Nora Radiyasti $^{1 * *}$, LestarUjianto ${ }^{2)}$, Baiq Erna Listiana ${ }^{2)}$ \\ 1) Alumnmi Fakultas Pertanian Universitas Mataram, Jln. Majapahit No 62 Mataram \\ 2)Dosen Fakultas Pertanian Universitas Mataram, Jln. Majapahit No 62 Mataram \\ *) Koresponden Author: Noraaradiyasti97@gmail.com
}

\begin{abstract}
ABSTRAK
Hubungan antar suatu sifat dengan sifat lainnya pada tanaman mempunyai arti penting dalam program pemuliaan tanaman untuk menentuan kriteria tak langsung. Peneltian ini bertujuan untuk mengetahui keragaan dan hubungan antar sifat populasi jagung lokal kebo hasil seleksi massa dalam sistem tumpang sari. Penelitian ini dilaksanakan pada bulan Mei sampai bulan Agustus 2018 di Lahan Percobaan Universitas Mataram Desa Nyurlembang, Kecamatan Narmada, Kabupaten Lombok Barat. Rancangan percobaan yang digunakan adalah Rancangan Acak Kelompok (RAK) terdiri dari 7 perlakuan yaitu $\mathrm{C} 0=$ populasi awal jagung local kebo, $\mathrm{C} 1=$ populasi siklus pertama, C2 = populasi siklus kedua, C3 = populasi siklus ketiga, C4 = populasi siklus keempat, C5 = populasi siklus kelima, dan $\mathrm{G}=$ varietas unggul Gumarang, yang masing-masing diulang sebanyak 3 kali sehingga menghasilkan 21 unit percobaan. Hasil penelitian menunjukkan sifat umur keluar bunga jantan, umur keluar bunga betina, jumlah daun, diameter batang, umur panen, dan diameter tongkol menunjukkan hasil yang berbeda nyata pada taraf $5 \%$ sedangkan pada sifat tinggi tanaman, bobot tongkol kering, panjang tongkol, jumlah biji per tongkol, jumlah baris per tongkol,bobot biji pipil kering per tongkol, dan bobot 1000 biji tidak berbeda nyata pada taraf 5\%, pada hasil koefisien korelasi bobot biji pipil kering dipengaruhi oleh sifat jumlah daun, panjang tongkol, diameter tongkol, dan bobot 1000 biji, pada populasi jagung lokal kebo dari siklus awal sampai pada siklus ke lima menunjukkan umur genjah dan memiliki daya hasil yang sama dengan varietas unggul Gumarang dan keragaan pada populasi Jagung Lokal kebo tidak berbeda dengan varietas Gumarang.
\end{abstract}

\begin{abstract}
The relationship between a property with other properties in plants has an important meaning in plant breeding programs to determine indirect criteria. This study aims to determine the performance and relationship between the characteristics of local kebo maize population resulting from mass selection in intercropping systems. This research was conducted from May to August 2018 at the Experimental Field of Mataram University in Nyurlembang, Narmada District, West Lombok Regency. The experimental design used was Randomized Block Design (RBD) consisting of 7 treatments namely $C O=$ initial population of local kebo corn, $C 1=$ first cycle population, $C 2=$ second cycle population, $C 3=$ third cycle population, $C 4=$ fourth cycle population, $C 5=f i f t h$ cycle population, and $G=$ Gumarang superior variety, each of which was repeated 3 times to produce 21 experimental units. The results showed the age of male flowers out, age of female flowers out, number of leaves, stem diameter, harvest age, and ear diameter showed significantly different results at the level of 5\% while the nature of plant height, dry ear weight, ear length, number of seeds per ear, the number of lines per ear, the weight of dry shelled seeds per ear, and the weight of 1000 seeds were not significantly different at the level of 5\%, in the correlation coefficient the weight of dry shelled seeds was influenced by the number of leaves, ear length, ear diameter and 1000 weights seeds, in the local kebo corn population from the initial cycle to the fifth cycle showed early maturity and had the same yield with Gumarang superior varieties and performance in the local Corn kebo population was not different from the Gumarang variety.
\end{abstract}

Kata kunci : keragaan, jagung local kebo, seleksi massa, tumpangsari Keywords: performance, local kebo corn, mass selection, intercropping 


\section{PENDAHULUAN}

Jagung sebagai salah satu komoditas pertanian penghasil karbohidrat sudah tidak asing lagi bagi masyarakat dunia. Komoditas ini merupakan bahan pangan sumber karbohidrat yang dapat mengganti bahan pangan beras. Bahkan, di beberapa daerah di Indonesia, jagung dijadikan sebagai bahan pangan utama. Jagung di samping sebagai bahan pangan, juga merupakan bahan pakan ternak dan bahan baku industri (Purwono dan Hartono, 2005). Menurut Badan Pusat Statistik (BPS, 2012), produksi jagung di Nusa Tenggara Barat (NTB) pada tahun 2012 sudah mencapai 1993.800 ton pipil kering, sedangkan pada tahun 2013 dapat diperkirakan mulai sedikit meningkat sekitar 198.300 ton pipil kering.

Usaha-usaha yang dapat dilakukan untuk meningkatkan daya hasil jagung antara lain dengan perbaikan cara bercocok tanam, pemupukan yang lebih intensif serta penggunaan varietas unggul yang berdaya hasil tinggi (Subandi, 1985). Salah satu tujuan dalam pemuliaan tanaman jagung, yaitu untuk memperoleh varietas unggul. Penggunaan varietas unggul merupakan salah satu syarat penting untuk mendapatkan produksi yang optimal. Namun, petani sering dihadapkan oleh sulitnya mendapatkan benih dari varietas unggul. Oleh karena itu, petani masih banyak menggunakan varietas lokal. Varietas jagung lokal kebo merupakan salah satu jagung lokal di pulau Lombok yang banyak digunakan karena hasilnya yang cukup baik dengan rata-rata produksi 4,2 ton/ha. Jagung lokal kebo merupakan jagung kultivar yang memiliki keragaman tinggi pada ukuran tongkolnya sehingga memungkinkan untuk dilakukan seleksi. Idris (1996), telah melakukan seleksi masa pada jagung lokal kebo. Seleksi massa adalah salah satu metode seleksi yang tertua untuk memilih bahan tanaman yang lebih baik pada generasi berikutnya. Keragaman yang tinggi secara berangsur-angsur akan menuju pada keseragaman. Oleh karena itu, keragaan (penampilan fenotip) dari awal seleksi (C0) hingga siklus ke 5 (C5) tentu sudah mengalami perubahan.

Seleksi massa dapat dilakukan dengan pengendalian atau tanpa pengendalian penyerbukan. Seleksi massa tanpa pengendalian penyerbukan lebih sederhana prosedurnya. Seleksi massa menggunakan petak terbagi ("grid system") telah banyak dilakukan untuk memperbaiki sifat tanaman seperti yang dilakukan oleh Yakop et. al(2005) pada jagung lokal Kebo. Jagung lokal kebo dalam sistem tanam tumpangsari telah diperbaiki hingga siklus ke 5 (C5) (Idris et al., 2003). Tumpangsari yang dilakukan ini adalah jagung dengan kacang tanah. Cara tumpangsari ini merupakan salah satu bentuk pertanaman campuran (polyculture) yang melibatkan dua jenis tanaman atau lebih pada areal lahan per tanaman dalam waktu yang bersamaan.

Dalam menentukan keragaan dari suatu kultivar jagung perlu dilakukan evaluasi. Evaluasi salah satunya untuk mengetahui keragaman genetik yang ada sehingga sumber-sumber genetik dapat dimanfaatkan secara optimal. Data hasil evaluasi akhir digunakan untuk mendeskripsikan suatu populasi. Kajian keragaan dan keragaman genetik sifat-sifat kuantitatif tanaman sangat membantu pemulia tanaman untuk menilai ekspresi suatu sifat disebabkan oleh genetik atau lingkungannya, dan menentukan individu tanaman yang terpilih dalam seleksi. Hubungan antar suatu sifat dengan sifat lainnya pada tanaman mempunyai arti penting dalam program pemuliaan tanaman. Informasi korelasi antar variabel hasil dengan hasil biji penting dalam penentuan seleksi. Apabila nilai koefisien tinggi, maka seleksi akan lebih efektif karena satu dengan sifat lainnya saling mempengaruhi (Jambormias, 2004). Berdasarkan hal tersebut, maka akan di lakukan penelitian tentang "Keragaan dan Hubungan Antar Sifat Populasi Varietas Jagung Lokal Kebo Hasil Seleksi Massa dalam Sistem Tumpangsari”.

\section{METODE PENELITIAN}

Penelitian ini menggunakan metode eksperimental yang dilaksanakan di lapangan. Penelitian ini dilaksanakan di Lahan Percobaan Universitas Mataram Desa Nyurlembang, Kecamatan Narmada, Kabupaten Lombok Barat. Waktu pelaksanaan penelitian ini berlangsung dari bulan Mei sampai dengan bulan Agustus 2018. Rancangan percobaan yang digunakan dalam percobaan ini adalah Rancangan Acak Kelompok (RAK) dengan 7 perlakuan, masing-masing perlakuan di ulang sebanyak 3 kali sehingga terdapat 21 unit percobaan. Sifat yang diamati adalah umur keluar bunga jantan, umur keluar bunga betina, tinggi tanaman, diameter batang, jumlah daun, umur panen, bobot tongkol kering, jumlah baris per tongkol, jumlah biji per tongkol, bobot biji pipil kering per tongkol dan bobot 1000 biji. Data hasil pengamatan dianalisis menggunakan analisis keragaman Analisis of variance (ANOVA) yang dilanjutkan dengan Uji Duncan Multiple Range Test (DMRT) 5\%.

\section{HASIL DAN PEMBAHASAN}

Berdasarkan hasil analisis keragaman, terdapat beda nyata pada taraf nyata $5 \%$ untuk sifat umur keluar bunga jantan, umur keluar bunga betina, jumlah daun, diameter batang, umur panen, bobot tongkol kering, panjang tongkol, dan diameter tongkol (Tabel 1). Sedangkan sifat yang tidak berbeda nyata pada taraf nyata 5\% terdapat pada sifat tinggi tanaman, jumlah biji per tongkol, jumlah baris per tongkol, bobot biji per tongkol, bobott biji pipil kering per tongkol dan bobot 1000 butir biji.

Pada Tabel 2., menunjukkan bahwa pada sifat umur keluar bunga jantan dan umur panen, semua siklus lebih genjah dibandingkan dengan Varietas Gumarang sebagai control. Umur keluar bunga betina rerata tertinggi pada varietas Gumarang dan rerata terendah pada populasi $\mathrm{C} 0$ dan $\mathrm{C} 1$, namun tidak berbeda dengan $\mathrm{C} 2$, dan $\mathrm{C} 3$. Umur keluar bunga jantan dan umur keluar bunga betina berhubungan dengan umur dan bunga betina maka 
semakin cepat pula umur panennya. Pernyataan ini di dukung oleh Koeswara (1982), bahwa lama pertumbuhan vegetative sangat mempengaruhi saat tanaman siap panen. Semakin awal tanaman berbunga, umur panen semakin cepat dan semakin lambat tanaman berbunga, umur panen juga semakin lambat. Jumlah daun Varietas Gumarang lebih tinggi dibandingkan dengan populasi lainnya, tetapi tidak berbeda nyata dengan $\mathrm{C} 4$, yang terendah terdapat pada $\mathrm{C} 2$, tetapi tidak berbeda nyata dengan $\mathrm{C} 0, \mathrm{C} 1$ dan $\mathrm{C} 5$.

Tabel 1. Rangkuman Hasil Analisis Keragaman Populasi Jagung Lokal Kebo Hasil Seleksi Massa Hingga Siklus ke-5

\begin{tabular}{llc}
\hline No & Sifat yang diamati & Signifikan 5\% \\
\hline 1 & Umur keluar bunga jantan (hari) & $\mathrm{S}$ \\
2 & Umur keluar bunga betina (hari) & $\mathrm{S}$ \\
3 & Tinggi tanaman (cm) & $\mathrm{NS}$ \\
4 & Jumlah daun (helai) & $\mathrm{S}$ \\
5 & Diameter batang (cm) & $\mathrm{S}$ \\
6 & Umur panen (hari) & $\mathrm{S}$ \\
7 & Bobot tongkol kering (g) & $\mathrm{NS}$ \\
8 & Panjang tongkol (cm) & $\mathrm{NS}$ \\
9 & Diameter tongkol (cm) & $\mathrm{S}$ \\
10 & Jumlah biji per tongkol & $\mathrm{NS}$ \\
11 & Jumlah baris per tongkol (baris) & $\mathrm{NS}$ \\
12 & Bobot biji pipil kering per tongkol (g) & $\mathrm{NS}$ \\
13 & Bobot 1000 butir biji (g) & $\mathrm{NS}$ \\
\hline
\end{tabular}

Keterangan : $\mathrm{S}=$ signifikan (berbeda nyata) pada taraf nyata $5 \%, \mathrm{NS}=$ non signifikan pada taraf nyata $5 \%$

Jumlah daun berhubungan dengan kemampuan menangkap energi cahaya matahari untuk fotosintesis. Banyaknya daun memiliki peluang besar untuk mengahasilkan fotosintat. Sebagian dari hasil fotosintat akan ditimbun di organ generative yaitu biji. Secara teoritis semakin banyak daun maka akan semakin banyak fotosintat yang dihasilkan. Hal ini didukung oleh Muhadjir (1998), bahwa sinar matahari yang diserap oleh daun digunakan untuk proses fotosintesis.

Tabel 2. Nilai Rata-rata dan Hasil Uji Lanjut DMRT pada sifat Jagung Lokal Kebo

\begin{tabular}{llllllll}
\hline \multirow{2}{*}{ Populasi } & \multicolumn{6}{l}{ Rerata Semua Sifat Yang diamati } \\
\cline { 2 - 7 } & UKBJ (hst) & UKBB (hst) & TT $(\mathrm{cm})$ & JD (helai) & DB (cm) & UP (hari) & BTK (gr) \\
\hline C0 & $42,33 \mathrm{a}$ & $44,33 \mathrm{a}$ & 175,33 & $10,17 \mathrm{ab}$ & $1,72 \mathrm{bc}$ & $75,33 \mathrm{a}$ & 104,83 \\
C1 & $42,00 \mathrm{a}$ & $44,33 \mathrm{a}$ & 183,00 & $9,97 \mathrm{ab}$ & $1,58 \mathrm{a}$ & $75,33 \mathrm{a}$ & 113,00 \\
C2 & $42,33 \mathrm{a}$ & $44,67 \mathrm{a}$ & 171,90 & $9,80 \mathrm{a}$ & $1,75 \mathrm{~cd}$ & $75,67 \mathrm{a}$ & 102,80 \\
C3 & $42,33 \mathrm{a}$ & $44,67 \mathrm{a}$ & 193,97 & $10,50 \mathrm{~b}$ & $1,71 \mathrm{abc}$ & $76,33 \mathrm{a}$ & 111,17 \\
$\mathrm{C} 4$ & $42,00 \mathrm{a}$ & $44,67 \mathrm{~b}$ & 189,90 & $10,63 \mathrm{c}$ & $1,59 \mathrm{ab}$ & $76,00 \mathrm{a}$ & 108,07 \\
C5 & $42,33 \mathrm{a}$ & $46,00 \mathrm{~b}$ & 180,70 & $10,30 \mathrm{ab}$ & $1,86 \mathrm{~d}$ & $77,00 \mathrm{a}$ & 108,40 \\
G6 & $53,67 \mathrm{~b}$ & $54,33 \mathrm{c}$ & 175,93 & $11,30 \mathrm{c}$ & $1,92 \mathrm{~d}$ & $83,00 \mathrm{~b}$ & 116,37 \\
\hline
\end{tabular}

Lanjutan Tabel 2.

\begin{tabular}{lllllll}
\hline \multirow{2}{*}{ Populasi } & \multicolumn{7}{c}{ Rerata sifat yang diamati } \\
\cline { 2 - 7 } & PT $(\mathrm{cm})$ & DT $(\mathrm{cm})$ & JBT $(\mathrm{biji})$ & JBRST (baris) & BBPKT $(\mathrm{gr})$ & B1000 $(\mathrm{gr})$ \\
\hline C0 & 14,12 & $4,07 \mathrm{ab}$ & 363,10 & 12,73 & 102,50 & 275,00 \\
C1 & 15,05 & $4,02 \mathrm{a}$ & 364,57 & 12,43 & 105,50 & 301,67 \\
C2 & 14,98 & $4,16 \mathrm{bc}$ & 372,27 & 12,37 & 107,33 & 301,67 \\
C3 & 15,37 & $4,17 \mathrm{bc}$ & 367,93 & 12,27 & 115,67 & 313,33 \\
C4 & 15,68 & $4,30 \mathrm{~cd}$ & 391,77 & 12,50 & 112,83 & 300,00 \\
C5 & 15,48 & $4,26 \mathrm{~cd}$ & 379,43 & 12,27 & 117,00 & 313,33 \\
G & 15,65 & $4,37 \mathrm{~d}$ & 421,90 & 12,87 & 113,87 & 288,33 \\
\hline
\end{tabular}


Keterangan :angka-angka yang diikuti dengan huruf yang sama menunjukkan beda nyata berdasarkan uji DMRT. KBJ (keluar bunga jantan), KBB (keluar bunga betina), TT (tinggi tanaman), JD (jumlah daun), DB (diameter batang), UP (umur panen), BTK (bobot tongkol kering per tongkol), PT (panjang tongkol), DT (diameter tongkol), JBT (jumlah biji per tongkol), JBRST (jumlah baris per tongkol), BBPKT (bobot biji pipil kering per tongkol), B1000 (bobot 1000 butir biji).

Diameter batang menunjukkan rerata tertinggi pada varietas Gumarang, namun tidak berbeda nyata dengan C5 dan C2 dan terendah pada populasi $\mathrm{C}$ 1, namun tidak berbeda dengan $\mathrm{C} 3$, dan $\mathrm{C} 4$. Hal ini menunjukkan semakin besar diameter batang maka semakin besar pula peluang proses pengangkutan unsur hara yang didalam tanah lebih banyak. Besar diameter batang juga menggambarkan kemampuan pertumbuhan tanaman yang mengarah pada semakin kokoh dan kuatnya tanaman, tanaman yang demikian juga memiliki kemampuan berkompetisi yang lebih baik (Uyek, dkk 2017). Umur panen pada setiap populasi menunjukann siklus umur panen lebih genjah dibandingkan dengan varietas Gumarang sebagai kontrol. Panjang tongkol pada populasi C4 lebih tinggi, dan terendah pada populasi $\mathrm{C}$, tetapi tidak berbeda dengan $\mathrm{C} 1, \mathrm{C} 2, \mathrm{C} 3 \mathrm{dan} \mathrm{C}$. Diameter tongkol varietas Gumarang lebih besar dibandingkan dengan populasi lainnya, namun tidak berbeda nyata dengan $\mathrm{C} 4$ dan C5 terendah terdapat pada populasi $\mathrm{C}$ 1, tetapi tidak berbeda dengan $\mathrm{C}$. Panjang tongkol maupun diameter tongkol antara populasi jagung lokal kebo memperlihatkan bahwa semakin besar siklus seleksinya maka panjang maupun diameter tongkol semakin bertambah ukurannya. Tongkol yang panjang dan diameter yang lebar menunjukkan semakin banyak butir biji jagung yang di peroleh (Idris dkk, 2018). C0 sampai Varietas Gumarang tidak memberikan pengaruh yang berbeda. Pada tabel 4.2 tinggi tanaman, bobot tongkol kering, jumlah biji per tongkol, jumlah baris per tongkol, bobot biji pipil kering per tongkol dan bobot 1000 biji pada setiap populasi.

Pada Tabel 3. menunjukkan bahwa bobot biji pipil kering berkorelasi positif nyata dengan sifat jumlah daun, panjang tongkol, diameter tongkol dan bobot 1000 biji, sedangkan dengan sifat yang lain tidak berkorelasi nyata. Panjang tongkol berkorelasi dengan semua sifat, kecuali dengan jumlah baris per tongkol tidak berkorelasi nyata. Diameter tongkol berkorelasi positif nyata dengan jumlah biji per tongkol dan bobot biji pipil kering per tongkol, kecuali bobot 1000 biji dan jumlah baris per tongkol tidak berkorelasi nyata. Jumlah biji berkorelasi dengan jumlah baris baris per tongkol dan tidak berkorelasi nyata dengan bobot 1000 biji dan bobot biji pipil kering per tongkol. Jumlah baris per tongkol berkorelasi negatif nyata dengan bobot 1000 biji. Bobot 1000 biji berkorelasi positif dengan bobot biji pipil kering per tongkol. Umur keluar bunga jantan berkorelasi positif nyata dengan umur keluar bunga betina, jumlah daun, diameter batang, umur panen, bobot tongkol kering, diameter tongkol, jumlah biji tanaman per tongkol,dan jumlah baris per tongkol kecuali tinggi tanaman, panjang tongkol, bobot 1000 biji dan bobot biji pipil kering per tongkol tidak beda nyata pada semua sifat yang diamati.

Tabel 3. Koefisien Korelasi antar Sifat yang diamati

\begin{tabular}{|c|c|c|c|c|c|c|c|c|c|c|c|c|c|}
\hline PER & UKBJ & UKBB & $\mathrm{TT}$ & JD & $\mathrm{DB}$ & UP & BTK & PT & DT & JBT & JBRST & B 1000 & $\begin{array}{l}\text { BBPK } \\
\mathrm{T} \\
\end{array}$ \\
\hline UKBJ & 1 & & & & & & & & & & & & \\
\hline UKBB & $0,989 *$ & 1 & & & & & & & & & & & \\
\hline TT & $-0,319$ & $-0,303$ & 1 & & & & & & & & & & \\
\hline JD & $0,811 *$ & $0,824^{*}$ & 0,201 & 1 & & & & & & & & & \\
\hline DB & $0,682^{*}$ & $0,739^{*}$ & $-0,494$ & 0,471 & 1 & & & & & & & & \\
\hline UP & $0,978^{*}$ & $0,995^{*}$ & $-0,223$ & $0,859^{*}$ & $0,744^{*}$ & 1 & & & & & & & \\
\hline BTK & $0,658^{*}$ & $0,662^{*}$ & 0,308 & $0,693^{*}$ & 0,205 & $0,682^{*}$ & 1 & & & & & & \\
\hline PT & 0,359 & 0,438 & 0,452 & $0,585^{*}$ & 0,193 & 0,497 & $0,543^{*}$ & 1 & & & & & \\
\hline DT & $0,619^{*}$ & $0,688^{*}$ & 0,077 & $0,801 *$ & $0,573 *$ & $0,733^{*}$ & 0,327 & $0,768^{*}$ & 1 & & & & \\
\hline JBT & $0,874^{*}$ & $0,902 *$ & $-0,128$ & $0,875^{*}$ & $0,56^{*}$ & 0,91 & $0,559^{*}$ & $0,653^{*}$ & $0,88^{*}$ & 1 & & & \\
\hline JBRST & $0,714 *$ & $0,647^{*}$ & $-0,45$ & $0,557^{*}$ & 0,288 & $0,596^{*}$ & 0,299 & $-0,205$ & 0,229 & $0,568 *$ & 1 & & \\
\hline B1000 & $-0,346$ & $-0,259$ & $0,548^{*}$ & $-0,160$ & $-0,074$ & $-0,19$ & 0,097 & $0,608^{*}$ & 0,136 & $-0,159$ & $-0,886^{*}$ & 1 & \\
\hline BBPKT & $\mathbf{0 , 2 5 8}$ & 0,360 & 0,493 & $0,568 *$ & 0,423 & 0,444 & $-\mathbf{0 , 3 3 7}$ & $\mathbf{0 , 8 5 1 *}$ & $0,761 *$ & 0,487 & $-\mathbf{0 , 3 3 7}$ & $0,669 *$ & 1 \\
\hline
\end{tabular}

Keterangan: *) Berkolerasi nyata apabila nilai koefisien korelasinya $\geq 0,53$

UKBJ (umur keluar bunga jantan), UKBB (umur keluar bunga betina), TT (tinggi tanaman), JD (jumlah daun), DB (diameter batang), UP (umur panen), Btk (bobot tongkol kering), PT (panjang tongkol), DT (diameter tongkol), JBT (jumlah biji per tongkol), JBRST (jumlah baris per tongkol), B1000 (bobot 1000 butir biji), BBPKT (bobot biji pipil kering per tongkol).

Umur keluar bunga betina berkorelasi positif nyata dengan sifat lainnya kecuali pada tinggi tanaman, panjang tongkol, bobot 1000 biji dan bobot biji pipil kering tidak beda nyata pada semua sifat yang diamati. Tinggi 
tanaman tidak berkorelasi atau tidak beda nyata dengan semua sifat, tetapi berkorelasi positif dengan bobot 1000 biji. Jumlah daun berkorelasi positif nyata dengan sifat lain kecuali dengan diameter batang dan bobot 1000 biji tidak beda nyata. Diameter batang berkorelasi positif nyata dengan umur panen, diameter tongkol dan jumlah biji tongkol, sedangkan tidak berkorelasi nyata dengan bobot tongkol kering, panjang tongkol, jumlah baris per tongkol, bobot 1000 biji dan bobot biji pipil kering. Umur panen berkorelasi positif nyata dengan bobot tongkol kering, diameter tongkol dan jumlah baris per tongkol, kecuali panjang tongkol, jumlah biji per tongkol, bobot 1000 biji dan bobot biji pipil kering per tongkol. Hubungan keterkaitan karakter yang satu dengan karakter yang lain bisa disebabkan oleh faktor genetik maupun faktor lingkungan. Faktor genetik utama yaitu adanya peristiwa pleiotropi dan linkage (Ambarwati, 2014).

\section{KESIMPULAN DAN SARAN}

Dari hasil dan pembahasan di atas maka dapat disimpulkan bahwa : Sifat umur keluar bunga jantan, umur keluar bunga betina, jumlah daun, diameter batang, umur panen, dan diameter tongkol menunjukkan hasil yang berbeda nyata pada taraf $5 \%$ sedangkan pada sifat tinggi tanaman, bobot tongkol kering, panjang tongkol, jumlah biji per tongkol, jumlah baris per tongkol,bobot biji pipil kering per tongkol, dan bobot 1000 biji tidak berbeda nyata pada taraf 5\%. Pada hasil koefisien korelasi bobot biji pipil kering di pengaruhi oleh sifat jumlah daun, panjang tongkol, diameter tongkol, dan bobot 1000 biji. Pada populasi jagung lokal kebo dari siklus awal sampai pada siklus ke lima menunjukkan umur genjah dan memiliki daya hasil yang sama dengan varietas Gumarang. Keragaan pada populasi jagung lokal kebo tidak berbeda dengan varietas Gumarang. Jumlah daun, panjang tongkol, dan diameter tongkol dapat dijadikan sebagai kriteria seleksi tidak langsung untuk perbaikan daya hasil jagung.

\section{DAFTAR PUSTAKA}

Ambarwati E. 2014. Pengantar Genetika Kuantitatif. Gadjah Mada University. Press.

Badan Pusat Statistik. 2012. Produksi jagung nasional. http://www.indonesiafinancetody.com/read/41474/ Produksi-Jagung-Nasional-Capai-1938-juta-ton [19 November 2018]

Idris. 1996. Pendugaan ragam genetik dan keeratan hubungan antar sifat dengan hasil pada jagung kultivar lokal kebo. [Tesis Magister, Umpublished]. Program Pasca Sarjana Universitas Brawijaya. Malang. 56 h.

Idris, Yakop U.M., Ujianto L. 2003. Kemajuan seleksi massa hingga siklus ke-5 (C5) pada jagung kultivar lokal kebo yang diseleksi berdasarkan sifat panjang tongkol. Fakultas Pertanian Unram. Mataram.

Idris, Sutresna I.W., Sudika I.W., Erna L.. 2018. Keragaman, heritabilitas dan Korelasi Jagung Kultivar Lokal Kebo Hasil Seleksi Massa Dalam Sistem Tumpangsari. Fakultas Pertanian. Universitas Mataram.

Jambormias, E., Sutjahjo S.H., Jusuf M., Suharsono. 2004. Keragaan, Keragaman Genetik dan Heritabilitas Sebelas Sifat Kuantitatif Kedelai (Glycine max (L.) Merill) pada Generasi Seleksi F5. Jurnal Pertanian Kepulauan. 3 (2):115-124.

Koeswara, J. 1982. Jagung. Departemen Agronomi. Institud Pertanian Bogor. 50 h.

Muhadjir, F. 1998. Karakteristik Tanaman Jagung. Hal 34-36. Dalam Subandi, M, Syam dan Adi Widjono (ed). Jagung. Balai Penelitian dan Pengembangan Pertanian, Pusat Penelitian Tanaman Pangan Bogor.

Purwono dan Hartono , 2011. Bertanam Jagung Unggul. Jakarta: Penebar Swadaya.

Subandi. 1985. Jagung. Pusat Penelitian dan Pengembangan Tanaman Pangan

Yakop U.M., Idris., Ujianto L. 2017. Perakitan Jagung Varietas Unggul Untuk Tumpangsari Melalui Seleksi Massa. Fakultas Pertanian. Universitas Mataram. 